\title{
Disseminated Cytomegalovirus Infection in a Patient with $R A G 2$ Mutation SCID Transmitted via Breast Feeding: A Case Report and Review of Literature
}

\author{
Asma Danish ${ }^{1, *}$, Samreen Kulsoom ${ }^{2}$, Saqib Hussain Ansari ${ }^{3}$, Tahir Sultan Shamsi ${ }^{1}$ \\ ${ }^{1}$ Department of Clinical Hematology, National Institute of Blood Disease \& Bone Marrow Transplantation Karachi, Pakistan. \\ ${ }^{2}$ Department of Pediatric Infectious Diseases, National Institute of Blood Disease \& Bone Marrow Transplantation Karachi, Pakistan. \\ ${ }^{3}$ Department of Pediatric Hematology, National Institute of Blood Disease \& Bone Marrow Transplantation Karachi, Pakistan.
}

\begin{abstract}
Cytomegalovirus (CMV) infection poses a serious threat to immunocompromised patients in early life. Transmission of CMV to newborn via breastfeeding is a recognized mode. In our case, the affected child presented with the aftermaths of CMV infection affecting gastrointestinal tract (GIT) and central nervous system (CNS) with over-whelming viral replication and via ingestion of infected breast milk many times a day. Worsening clinical manifestations prompted the investigations for a possible primary immune deficiency (PID) disorder, and rising CMV copies in blood despite institution of anti-CMV therapy led to check other body fluids of the infant. There were no viral copies detected in mother's blood sample; so breast milk was tested to identify the source of CMV being transmitted to him. Here we describe an unusual case of RAG2 gene mutation induced PID presenting clinically as severe combined immunodeficiency (SCID) phenotype rather than Ommen's syndrome, and acquired CMV infection via breast milk.
\end{abstract}

Keywords: Breastfeeding, RAG2 mutation SCID, CMV, Seropositivity, Meningoencephalitis, Polyradiculopathy.

\section{INTRODUCTION}

Cytomegalovirus is a ubiquitous organism commonly shed in body fluids saliva, urine, genital secretions, blood and breast milk. Women who have had CMV infection in past remain seropositive for CMV IgG antibodies. Infants can acquire non-congenital CMV infection at the time of birth or through breast feeding afterwards if mother is seropositive.

All types of CMV infection, whether primary or reactivation, usually present with either a mild prodrome, to no symptom at all in immunocompetent children, protection conferred to them by the passage of maternally transmitted antibodies during third trimester of pregnancy [1]. On the contrary, low birth-weight preterm neonates, children with congenital immunodeficiency disorders such as severe combined immunodeficiency, allograft recipients, splenectomized patients, and patients receiving immunosuppressive chemotherapy are all susceptible to not only acute symptomatic disease of varying severity but to development of long term sequelae as well [2].

Isolation of cytomegalovirus from human breast milk was first reported in the late 1960s and since then it's routinely isolated [3]. Babies breast fed by mothers excreting CMV in their milk are commonly asymptomatically infected in contrast to those who are formula fed [4]. It has been observed in a number of studies that transmission of CMV from breast milk occurs in 25 to $50 \%$ of term infants born from seropositive mothers [5]. Thus, preterm babies and immunocompro-

*Address correspondence to this author at the Department of Clinical Hematology National Institute of Blood Disease \& Bone Marrow Transplantation Karachi, Pakistan. E-mail: asmakarm@hotmail.com mised patients pose additional risk of not only acquiring the disease via mother's milk but to present with disseminated disease as well [6].

CMV excretion from breast milk of seropositive women begins during the first week postpartum peaking at 4-8 weeks after delivery, and declining steadily thereafter. Infectious virus and CMV DNA and RNA have been isolated from breast milk of $40 \%-97 \%$ of CMV-seropositive lactating women [7].

This case report is about the transmission of CMV through breast milk in an infant with primary immune deficiency. The purpose of discussing this case is to highlight unusual aspects of CMV transmission in an immunocompromised host and its disseminated presentation, which might distract a clinician's logical perspective of treating a specific illness.

\section{CASE SUMMARY}

A 6 months old infant presented with chronic diarrhea for 3 months. There was temporary improvement with broad spectrum antibiotics but the primary complaint was persistent. After being treated in multiple hospitals he was referred with suspicion of primary immune deficiency disorder. Throughout this time he was on exclusive mother feed. At presentation to us he was passing loose watery stools with crampy abdominal pain \& irritability. Initial examination showed a failure to thrive child with signs of septic shock. He had bilateral non pitting pedal edema with no lymphadenopathy and visceromegaly.

Baby had remained virtually asymptomatic for 3 months before disease onset. He was a first born of cousin parents, 
with normal antenatal and postnatal courses. He was vaccinated according to expanded programme of immunization of our country. Up till 4 months of age, he was growing well above the normal centiles for height and weight and was achieving developmental milestones at appropriate ages.

On the basis of his clinical findings our differentials included primary immune deficiency disorder particularly SCID, protein losing enteropathy, primary intestinal lymphangiectasia or secondary due to chronic intestinal infections and ataxia telangiectasia after his milestones started to regress.

His baseline investigations showed $\mathrm{Hb} 8.2 \mathrm{~g} / \mathrm{dl}$, ANC $0.09 \times 10^{9} / \mathrm{L}$, ALC $0.13 \times 10^{9} / \mathrm{L}$, platelet count of $181 \times 10^{9} / 1$ and hypoalbuminemia. . For primary immunodeficiency disorder in this child immunoglobulin levels were sent which showed extremely low levels of IgA, IgG, IgM antibodies \& lymphocyte subset analysis showed $\mathrm{CD}+3, \mathrm{CD}+8$ cells 7/ul, CD19+ cells 91/ul, NK cells 140/ul. His NGS (next generation sequencing) panel showed homozygous $R A G 2$ mutation due to stop codon at 307 position confirming his disease as Severe combined immunodeficiency.

His inflammatory markers were raised while bacterial cultures showed no growth. His viral PCR came out to be positive for CMV antigen with 97000 copies/ml initially. He was started on therapeutic dose of intravenous Ganciclovir but his CMV copies continued to rise.

Neurologically his condition was worsening with regression of milestones \& generalized hypotonia. His CSF analysis was normal but PCR of CMV showed 30,000 copies $/ \mathrm{ml}$ of CMV antigen. MRI brain was also done which showed mild prominence of extra cerebral CSF spaces with prominence of lateral sulci bilaterally.

His poor response to treatment was a great concern. Considering other routes of continuous transmission of CMV, his mother was evaluated with viral serology and PCR initially. CMV antigen was not detected in mother's serum but she was seropositive with IgG antibodies. As the patient was on exclusive mother feed we sent CMV PCR of mother's milk \& it contained 10000 copies $/ \mathrm{ml}$.

This finding confirmed our suspicion that child is exposed to CMV via mother's milk and hence not showing response to treatment. We stopped mother's milk and switched the child to formula milk. Within a couple of days CMV titers started to fall. Clinically irritability and gastrointestinal symptoms improved but CNS damage couldn't be reversed..

\section{DISCUSSION}

Human cytomegalovirus infection is the commonest cause of perinatally acquired infections throughout the world as a result of transmission during childbirth, breast feed or by blood transfusion; vertical transmission is more common than horizontal [8].
One of the important aspects of our case was the mode of transmission of CMV via breast milk. Amongst different modes of vertically transmitted CMV, trans-mammary spread is the most common accounting for majority of infants who acquire CMV in first year of life [9]. CMV is a member of the herpes virus family, which has a strong tendency to become latent and reactivate. Peripheral blood mononuclear cells appear to be the most common site of latency [10].

Interestingly however, reactivation of CMV has been mostly found restricted to the lactating breast, the site of latency, virus production, replication, and mode of reactivation remains obscure. Most of the virus was found to be free rather than cell associated and peak levels of CMV were observed around 1 month after delivery [11]. It has been extensively studied now that CMV DNA been isolated from cell-associated and whey fractions in the breast milk of $40 \%-97 \%$ of CMV-seropositive lactating women [12].

An immunocompetent infant breastfed by its CMV seropositive mother might not show any overt symptom but an immunocompromised child as our patient presented, or a premature infant can have severe disseminated disease. Claudia $\mathrm{P}$ et al demonstrated severe perinatally acquired CMV meningitis in a 35 days old child with SCID treated before bone marrow transplant [13].

Our patient had severe CMV enterocolitis, encephalitis and ultimately severe hypotonia and loss of milestones. Gastrointestinal and retinal involvement is commoner symptoms of $\mathrm{CMV}$ infection than CNS involvement. Neurological manifestations due to CMV, including meningoencephalitis, encephalitis, ventriculoencephalitis, radiculomyelopathy and peripheral neuropathy, is identified in less than $1 \%$ of all acquired CMV infected cases [14]. Acquired CMV encephalitis is lethal in immunocompromised patients and imaging findings of acquired CMV infection often are nonspecific, needing specific molecular techniques as PCR to detect CMV or to isolate the organism by tissue culture [15]. Most common MRI findings include few areas showing diffuse or patchy increased signal intensities in white matter resulting from demyelination, and enhancement in the periventricular sub-ependymal lining along the lateral ventricles, septum pellucidum, corpus callosum and fornices as a result of ventriculitis [16]. Our patient's CSF analysis although showed no pleocytosis or raised proteins, his CMV PCR was positive and MRI findings were indicative of ventriculoencephalitis (Fig. 1a, b). 

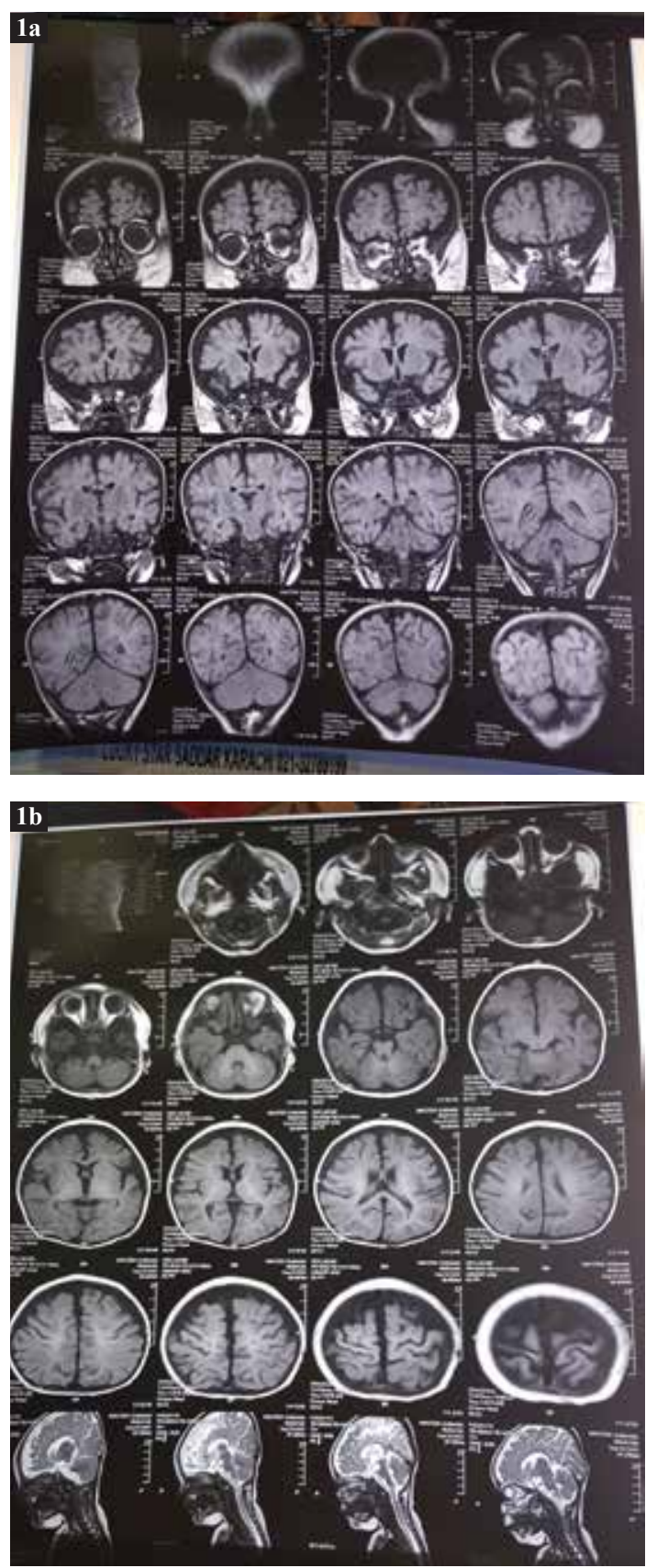

Fig. (1). Mild Prominence of Extra Cerebral CSF spaces with Prominence of Lateral Sulci Bilaterally.

In our case patient experienced generalized hypotonia as well which led us to believe that he might be experiencing other manifestations of CMV induced CNS disease especially polyradiculoneuropathy mostly found in immunocompromised individuals. Some studies have used the presence of a CSF polymorphonuclear pleocytosis in patients presenting with subacute onset flaccid paraparesis as being diagnostic of polyradiculoneuropathy, which might not even be present in CMV encephalitis, even when CMV PCR of CSF is negative
[17]. In our patient however, even though the symptoms were suggestive, CSF analysis did not show any abnormality. In such cases MRI findings in the spine, EMG, and nerve conduction studies might prove beneficial.

\section{CONCLUSION}

Our case emphasized the fact that children who are born with primary immune deficiency disorders should be investigated for congenital and acquired infections, CMV being the most lethal one. Breast milk is the most common route for acquisition of perinatal infection and alteration in management of immunocompromised newborn is essential, keeping in view the catastrophic outcome of breast feeding in such case.

\section{DATA AVAILABILITY}

Case report data used to support the findings of this study are currently under embargo while the research findings are commercialized. Requests for data, after publication of this article, will be considered by the corresponding author.

\section{FUNDING STATEMENT}

None.

\section{CONFLICT OF INTEREST}

Declared none.

\section{ACKNOWLEDGEMENTS}

Declared none.

\section{REFERENCES}

[1] Bryant P, Morley C, Garland S, Curtis N. Cytomegalovirus transmission from breast milk in premature babies: Does it matter. Arch Dis Child 2002; 87: F75-7.

DOI: $10.1136 /$ fn.87.2.F75

[2] Onorato IM, Morens DM, Martone WJ, Stansfield SK. Epidemiology of cytomegaloviral infections: Recommendations for prevention and control. Rev Infect Dis 1985; 7: 479-97.

DOI: $10.1093 /$ clinids/7.4.479

[3] Hamprecht K, Maschmann J, Vochem M, Dietz K, Speer CP, Jahn G. Epidemiology of transmission of cytomegalovirus from mother to preterm infant by breastfeeding. Lancet 2001; 357: 513-8. DOI: 10.1016/S0140-6736(00)04043-5

[4] Vochem M, Hamprecht K, Jahn G, et al. Transmission of cytomegalovirus to preterm infants through breast milk. Pediatr Infect Dis J 1998; 17: 53-8.

DOI: $10.1097 / 00006454-199801000-00012$

[5] Meier J, Lienicke U, Tschirch E, Kruger DH, Wauer RR, Prosch S. Human cytomegalovirus reactivation during lactation and mother-to-child transmission in preterm infants. J Clin Microbiol 2005; 43: 1318-24.

DOI: $10.1128 / J C M .43 .3 .1318-1324.2005$

[6] Forsgren M. Cytomegalovirus in breast milk: Reassessment of 
pasteurization and freeze- thawing. Pediatr Res 2004; 56(4): 526-8. DOI: 10.1203/01.PDR.0000143155.84802.A3

[7] Omarsdottir S, Casper C, Zweygberg Wirgart B, Grillner L, Vanpee M. Transmission of cytomegalovirus to extremely preterm infants through breast milk. Acta Paediatr 2007; 96(4): 492-4. DOI: 10.1111/j.1651-2227.2007.00224.x

[8] Bhide A, Papageorghiou AT. Managing primary CMV infection in pregnancy. BJOG 2008; 115: 805-7. DOI: $10.1111 / \mathrm{j} .1471-0528.2008 .01728 . x$

[9] Robert FP, Brenna A. Mother-to-child transmission of cytomegalovirus and prevention of congenital infection. J Pediatr Infect Dis Soc 2014; 3(Suppl 1): S2-S6.

DOI: $10.1093 /$ jpids/piu069

[10] Taylor- Weideman, J, Hayhurst GP, Sissons JGP, Sinclair JH. Induction of endogenous human cytomegalovirus gene expression after differentiation of monocytes from healthy carriers. J Virol 1994; 68: 1597-1604.

[11] Johannes M, Uta L, Edda T, et al. Human cytomegalovirus reactivation during lactation and mother-to-child transmission in preterm infants. J Clin Microbiol 2005; 43(3): 1318-24. DOI: $10.1128 / J C M .43 .3 .1318-1324.2005$

[12] Capretti MG, Lanari M, Lazzarotto T, et al. Very low birth weight infants born to cytomegalovirus-seropositive mothers fed with their mother's milk: A prospective study. J Pediatr 2009; 154(6): 842-8. DOI: 10.1016/j.jpeds.2008.12.046

[13] Claudia P, Vicetti M, Asuncion M, Octavio R, Monica I, Pablo J. Cytomegalovirus meningitis in an infant with severe combined immunodeficiency. J Pediatr 2016; 173: 235-7. DOI: $10.1016 /$ j.jpeds.2016.02.054

[14] Seok JH, Ahn K, Park HJ. Diffusion MRI findings of cytomegalovirus-associated ventriculitis: A case report. Br J Radiol 2011; 84(1005): e179-e81.

DOI: $10.1259 / \mathrm{bjr} / 31561378$

[15] Fink KR1, Thapa MM, Ishak GE, Pruthi S. Neuroimaging of pediatric central nervous system cytomegalovirus infection. Radiographics 2010; 30(7): 1779-96.

DOI: $10.1148 /$ rg.307105043

[16] Thurner MM, Thurnher SA, Schindler E. CNS involvement in AIDS: Spectrum of CT and MR findings. Eur Radiol 1997; 7: 1092-7. DOI: $10.1007 / \mathrm{s} 003300050260$

[17] So YT, Olney RK. Acute lumbosacral polyradiculopathy in acquired immunodeficiency syndrome: experience in 23 patients. Ann Neurol 1994; 35: 53-8.

DOI: 10.1002/ana.410350109 